\title{
Research on the Model of Consumer Health Information Seeking Behavior via Social Media
}

\author{
Juan Chen, Xiaorong Hou, Wenlong Zhao* \\ College of Medical Informatics, Chongqing Medical University, Chongqing, China \\ Email: chenjuancqmu@163.com, hxrhelen@163.com, “cqzhaowl@163.com
}

Received 20 June 2016; accepted 8 August 2016; published 11 August 2016

Copyright (c) 2016 by authors and Scientific Research Publishing Inc.

This work is licensed under the Creative Commons Attribution International License (CC BY). http://creativecommons.org/licenses/by/4.0/

(c) $\stackrel{\text { (i) }}{\mathrm{EY}}$ Open Access

\section{Abstract}

Purpose: We aim to create a model of consumer health information seeking behavior via social media, then to have a better understand of it. After that further efforts should be made to provide targeted recommendations for media managers to promote health communication via social media. Methods: Our custom model was derived from literature review, empirical research was tested by the use of questionnaire investigation, and then the collected data were analyzed by structural equation model tool SmartPLS. Finally, the custom model was modified according to the experimental results of SmartPLS. Results: A total of 239 (66.39\%) of the respondents were female and 121 (33.61\%) were male. The maximum of two stages of age were 18 - 29 (70.56\%), 30 - 39 (13.89\%). Wechat (60.28\%), QQ Zone (55.22\%), Micro-blog (48.89\%) were the most commonly used social media to obtain health information. About $44.72 \%$ of respondents used social media to obtain health information multiple times a day. The whole numerical values of AVE, cronbach's alpha, CR and square roots of AVE were above the benchmarks of themselves and showed great reliability and validity. All the 11 hypotheses had obvious statistical significance, the P-value of eight path coefficients exhibited $<0.001$, one path coefficient exhibited $<0.01$ and two path coefficients exhibited $<0.05$. Conclusions: A suitable model of consumer health information seeking behavior via social media was created and some inner relationships were found. Namely, gratification of health information and its platform had a positive effect on attitudes toward health information seeking behavior. Health information literacy and health status were proved to have a significant influence on attitudes toward health information seeking behavior, subject norms and perceived behavioral control respectively. In addition, attitudes toward the health information seeking behavior, subject norms and perceived behavioral control were proved to positively associate with health information seeking behavior intention.

${ }^{*}$ Corresponding author.

How to cite this paper: Chen, J., Hou, X.R. and Zhao, W.L. (2016) Research on the Model of Consumer Health Information Seeking Behavior via Social Media. Int. J. Communications, Network and System Sciences, 9, 326-337. 


\section{Keywords}

\section{Health Information Seeking Behavior, Research Model, Structural Equation Model, Social Media}

\section{Introduction}

The penetration of social media into modern society has become a worldwide cultural phenomenon; social networks allow users to connect with each other. The widely use of social media facilitated the creation and sharing of user-generated content in a collaborative and social manner [1]. Meanwhile, social media serves as a communication channel that facilitates health information sharing and more importantly cultivates community capacity focused on environment health promotion among people [2]. Since social media has become lowered the barrier to entry, health information seeking behavior has become more common. Increasingly, consumers engage in health information seeking via the social media, a basic tenet of consumer health information seeking is that access to quality electronic health resources empowers the public by increasing knowledge and improving decision-making. The social media played a major role in making this information accessible [3]. Using social network to gather health information was an activity that has remained consistently popular with most users over the last seven years of polling by the Pew Internet \& American Life Project and other research organizations. It was reported that more than 113 million adults have searched for health information online [4]. A great many health seekers said the resources they found on the Web had a direct effect on the decisions they made about their health care and on their interactions with doctors [5].

In this study, we aim to create a model of consumer health information seeking behavior via social media based on integrated model drawn from two theories: the theory planned behavior and the uses and gratifications approach from mass communication research. Combined with their influencing factors, we attempt to investigate how and why consumers use health-related social media, so as to have a better understand of it.

\section{Research Background}

Given the rapid changes in the communication landscape brought about by participative internet use and social media, it is important to develop a better understanding of these technologies and their impact on health communication. The first step in this effort is to create a model to identify the characteristics of current social media use on health information seeking and its influence factors [6]. Up-to-date reporting of current social media use for health information seeking will monitor the growth of social media and inform health promotion.

\subsection{Health Information Seeking Behavior}

Lambert and Loiselle had point out that explicit definitions of Health Information Seeking Behavior (HISB) were difficult to locate, and there was no apparent dominant definition. Typically, definitions are inferred by the purpose or focus of the article. Subsequently, some scholars had defined health information seeking behavior from the scene, concrete action mode and other different angles of concepts [7]. Rees and Bath indicated that HISB were the urge to confront oneself with the threatening situation by means of seeking more information about it [8]. Generally speaking, the broad sense attributed to HISB related to the ways in which individuals go about obtaining information, including information about their health, health promotion activities, risks to one's health, and illness. Seeking information about one's health is increasingly documented as a key coping strategy in health promoting activities and psychosocial adjustment to illness.

Prior research focused on factors that affect individual's willing and attitude about information seeking. These constructs include human computer interactions (e.g. information resources and information retrieval) [3], beliefs about information (e.g. type, amount, and value), organizational factors (e.g. Organizational norms and social aspects) [9]. Longo and Schubert pointed out health literacy makes a difference in consumers' ability to understand and use information. Associating with these achievements, we could reasonably assume that consumers' behavior for health information seeking via social media will be guided by health information literacy and gratification of social media [10]. 


\subsection{Health Information Literacy}

The concept of health information literacy was put forward by Medical Library Association (MLA) in July 2003, based on the combination of definition of health literacy and information literacy respectively defined by Department of Health and Human Services (DHHS) and American Library Association (ALA) [11]. As defined by the MLA, health information literacy was "the set of abilities needed to recognize a health information need; identify likely information sources and use them to retrieve relevant information; assess the quality of the information and its applicability to a specific situation; analyze, understand, and use the information to make good health decisions.” [12]. Thus, health information literacy plays an important role in the whole process of searching for health information via social media.

\subsection{Gratifications of Social Media}

Gratifications are conceptualized as "need satisfactions”, which are obtained when a person's needs are met by certain types of media sources that match their expectations [13]. The concept of gratifications of social media derived from the uses and satisfaction theory which [14] posits that personal motivations for using specific media (e.g. gratifications sought) are influenced by both the belief that the media possess certain characteristics and the subjective evaluation of whether each characteristic is a positive or negative attribute. The emphasis here is on the uses of social media in meeting the felt needs of the consumer which contains the gratification of information and gratification of information platform described below.

\subsection{Theory of Planned Behavior (TPB)}

As the most widely endorsed model in applied social psychology the theory of planned behavior (TPB) has received considerable attention in the literature and has met with some degree of success in predicting various behaviors in an expectancy value model of attitude-behavior relationships [15]. In the theory of TPB, four social cognitive components: behavior intentions, attitude toward the behavior, perceived behavioral control, and subjective norms could be identified to predict individuals' behaviors [16]. Behavior intentions represent one's motivation in a conscious plan or decision and tend to be a strong predictor of behavior. Attitudes toward the behavior are conceptualized as the degree to which performance of behavior is positively or negatively valued. Subjective norms refer to the perception of social pressure and motivation that people perceived evaluation of important others supporting or not supporting the behavior. Perceived behavioral control is defined as the perceived degree of difficulty in performing the behavior. These three factors are proposed to predict intention [17]. In our study, the TPB model was cited to analyze the attitude-behavior relationships of health information seeking behavior, as shown in Figure 1.

\section{Preliminary Research Model and Hypotheses}

A preliminary custom model was formulated according to above-mentioned analysis results. This model contained seven variables: health information literacy, gratification of information, gratification of information

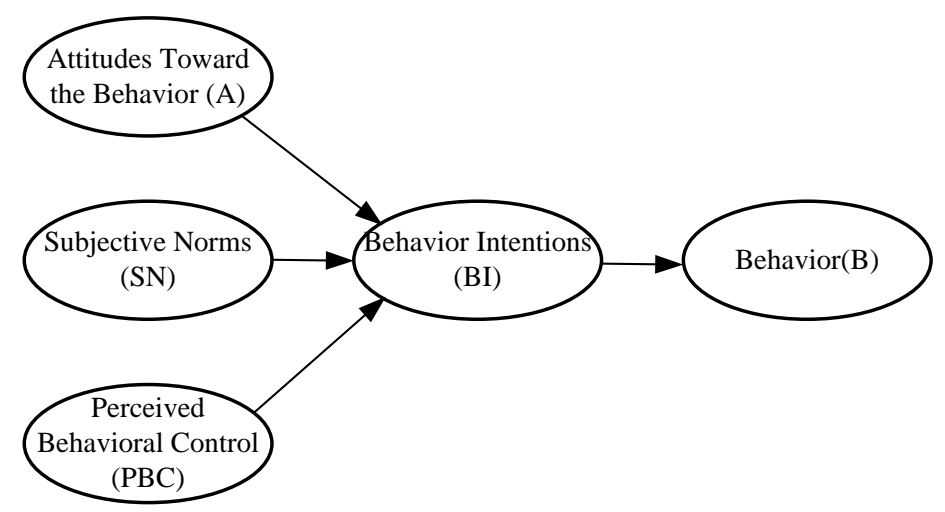

Figure 1. TPB model. 
platform, attitudes toward the behavior, subjective norms, perceived behavioral control and behavior intention. The complete research model is presented in Figure 2.

Health information literacy is crucial as people are expected to take responsibility for their own health care and health-related decisions [18]. People with low health information literacy tend to have lower levels of attitudes toward searching related health information via effective ways, as well as limited practical and instrumental knowledge related to searching related health information to self-managed treatment and care [19]. Consumers with limited health literacy may lack either internet access or skills necessary to utilize this information. Nonetheless, consumer at all health literacy levels may prefer other primary sources to obtain health information [20]. In briefly, Lower health information literacy could also affect subject norms and perceived behavioral control. Thus we hypothesized as below.

H1 Health information literacy (HIL) is positively associated with the attitudes toward the health information search behavior via social media (A).

H2 Health information literacy (HIL) is positively associated with subject norms (SN) that is to say the perception of social pressure and motivation.

H3 Health information literacy (HIL) is positively associated with perceived behavioral control (PBC) namely the perceived degree of difficulty in performing the behavior.

In addition to health information literacy, gratifications play an important role in health information seeking behavior. Sundar and Limperos pointed out that across the landscape of uses and gratifications studies from 1940 to 2011, two trends are noteworthy [21]: 1) as we move from old to newer media, it appeared that new gratifications do emerge with new technology. 2) Some broad gratifications, especially those related to social and information functions, tended to get more nuanced and specific with newer media. Social media as the newest media searching for health information meet new gratifications for us. In this model, two gratification factors are included.

Gratification of information platform is defined as the gratifications brought up after using social media platform to search for related health information in this article. It contains usability and functionality two factors. The design and usability aspects of websites were accepted as a key factor to its success [22]. Nathan and Yeow showed that the use of color and font had the highest effect on overall web usability, followed by clarity of goals in website, trustworthiness of website, use of graphic and multimedia, interactivity of website, ease of web navigation and finally download speed of website [23].

Gratification of information has long been considered closely related with the attitudes toward searching health information on different kinds of social media and platform use. Turban and Gehrke [24] showed that the

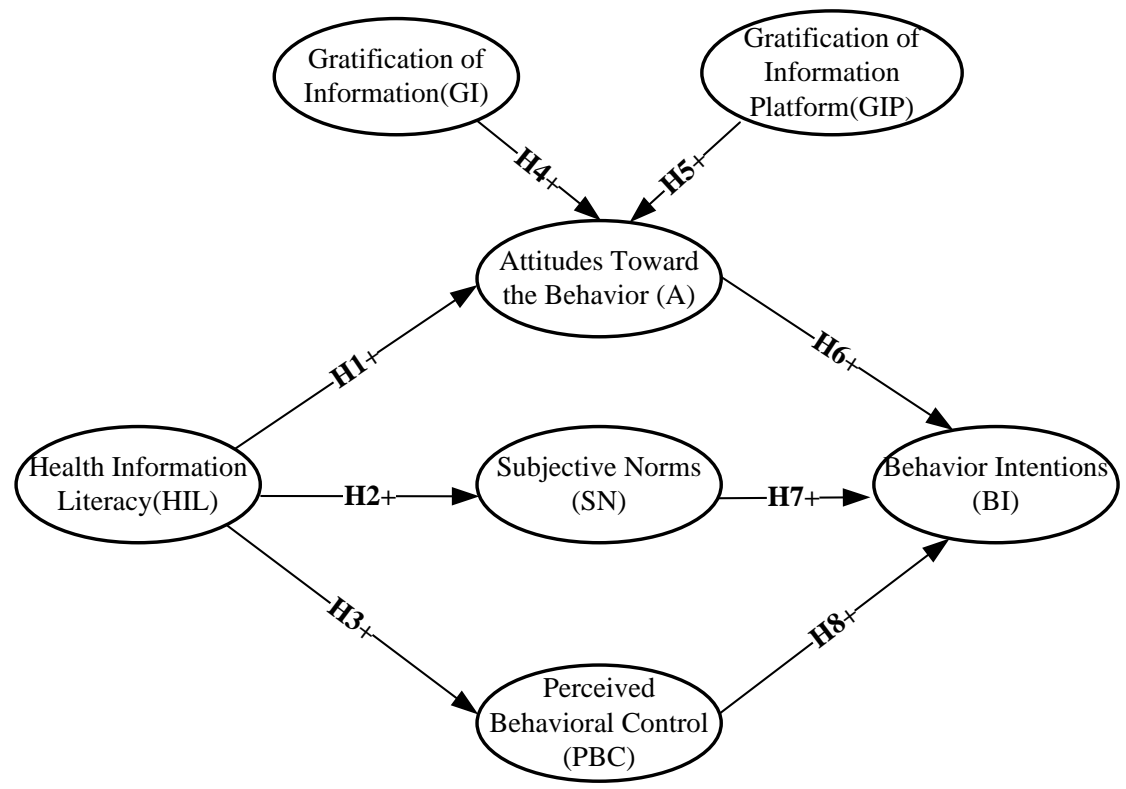

Figure 2. Preliminary research model. 
degree of satisfaction to the web site provided information directly decides the future of potential consumers. Information satisfaction is generally measured by the quality of the information provided by social media, such as Doll, Torkzadeh [25] proposed the information content, information form and system output as the usage to evaluate information satisfaction. In this paper, the satisfactions of health information seeking behavior should be included the content and the form of social media. Thus we hypothesized as below.

H4 Gratification of information platform (GIP) is positively associated with the attitudes toward the health information seeking behavior via social media (A).

H5 Gratification of information (GI) is positively associated with the attitudes toward the health information seeking behavior via social media (A).

According to the TPB model, an individual's behavior can be predicted based on attitudes toward the behavior (A), subjective norms (SN), perceived behavioral control (PBC), and especially, behavior intentions (BI). It has been proven that the more positive attitudes and subjective norms consumers hold, the greater perceived behavioral control regarding a behavior they represent, consumers were more likely to intend to perform that behavior. Similarly, the stronger intention consumer hold, they were more likely to perform the behavior. Thus we hypothesized as below.

H6 Attitudes toward the behavior (A) is positively associated with behavior intentions (BI).

H7 Subjective norms (SN) is positively associated with behavior intentions (BI).

H8 Perceived behavioral control (PBC) is positively associated with behavior intentions (BI).

\section{Research Methods and Data Collection}

\subsection{Methods}

Questionnaire survey was used to collected data which included two parts. The first part asked our respondents about their basic information, the second part contained questions measuring consumer health information seeking behavior via social media and its effects. Each item corresponding to the constructs was measured by a 5-point Likert scale. Constructs including gratifications, health information literacy, attitudes, subjective norms, perceived behavioral control were with answer choices ranging from strongly disagree (1) to strongly agree (5). Then the collected data was analyzed by structural equation model tool SmartPLS, since the PLS algorithm is a components-based structural equation modeling technique, "allowing each indicator to vary in how much it contributes to the composite score of the latent variable”, thus being “preferable to other techniques” [26].

\subsection{Data Collection}

The survey was administered in two ways. Online surveys were distributed for a month through Questionnaire star, an online survey website providing convenient and functional designing and administering questionnaires, paper-and-pencil surveys were distributed to people occasionally nearby hospital at the same time. We explained the purpose of our study and solicited their participation throughout the process to increase accuracy and response rate, furthermore to be eligible, all participants had to be over the age of 18, able to read and write Chinese, and provide consent. Finally, 400 questionnaires were sent out in a chance encounter. A total of 376 questionnaires were collected, the recovery efficiency was $94.00 \%$, in which 360 samples were effective, and the effective rate was $95.74 \%$.

\section{Data Analysis and Results}

\subsection{Demographic of Respondents}

Table 1 summarizes the demographic profile of respondents. A total of 239 (66.39\%) of the respondents were female and 121 (33.61\%) were male. The maximum of two stages of age were18 - 29 (70.56\%), 30 - 39 (13.89\%). Wechat (60.28\%), QQ Zone (55.22\%), Micro-blog (48.89\%) were the most commonly used social media to obtain health information. About $44.72 \%$ of respondents used social media to obtain health information multiple times a day.

\subsection{Reliability and Validity Evaluation}

The measurement model specifies the relationships between the manifest variables and the latent variables. The 
Table 1. Demographic of respondents.

\begin{tabular}{|c|c|c|c|c|c|}
\hline Category & Item & Percentage (\%) & Category & Item & Percentage (\%) \\
\hline \multirow{5}{*}{ Age } & $18-29$ & 70.56 & \multirow{5}{*}{$\begin{array}{l}\text { Ever used } \\
\text { we-media }\end{array}$} & QQ Zone & 93.33 \\
\hline & $30-39$ & 13.89 & & Renren Inc & 7.78 \\
\hline & $40-49$ & 6.39 & & Micro-blog & 48.89 \\
\hline & $50-59$ & 3.90 & & Wechat & 60.28 \\
\hline & Above 60 & 5.20 & & Blog & 7.50 \\
\hline \multirow{2}{*}{ Gender } & Male & 33.61 & & tieba & 1.67 \\
\hline & Female & 66.39 & \multirow{11}{*}{$\begin{array}{l}\text { The most } \\
\text { commonly used } \\
\text { we-media to } \\
\text { obtain health } \\
\text { information }\end{array}$} & Facebook & 28.33 \\
\hline \multirow{6}{*}{ profession } & Student & 44.72 & & Other & 10.30 \\
\hline & Teacher & 15.00 & & QQ Zone & 55.22 \\
\hline & $\begin{array}{l}\text { Civil servants/public in- } \\
\text { stitution staff }\end{array}$ & 14.72 & & Renren Inc & 7.78 \\
\hline & Enterprise staff & 15.83 & & Micro-blog & 48.89 \\
\hline & Free profession & 3.89 & & Wechat & 60.28 \\
\hline & Other & 5.83 & & Blog & 7.50 \\
\hline \multirow{4}{*}{$\begin{array}{l}\text { frequency of } \\
\text { health } \\
\text { information } \\
\text { seeking }\end{array}$} & Multiple times/day & 44.72 & & tieba & 1.67 \\
\hline & Once/day & 19.17 & & Facebook & 28.33 \\
\hline & Several times/week & 10.83 & & Other & 10.30 \\
\hline & seldom & 25.28 & & & \\
\hline
\end{tabular}

assessment of the measurement model includes Average Variance Extracted (AVE), an investigation of reliability coefficients Cronbach's alpha and Composite Reliability (CR) coefficients. AVE indicated what percentage of the variance of the construct is explained by an individual item. In this study, all constructs demonstrated AVE values were between 0.526 and 0.692 (see Table 2), which were higher than the benchmark of 0.5 [27]. Internal consistency was assessed by means of Cronbach's alpha coefficients and CR coefficients which values were calculated for each of the multi-item factors included in the model. CR coefficients were displayed for each of the variables and ranged from 0.811 to 0.899 , all constructs displayed a higher CR than the benchmark of 0.70 [27] [28]. The Cronbach's alpha coefficients in Table 2 most ranged from 0.713 to 0.860 and were above the suggested level of 0.70 [29], excepted BI (0.653), which was a little lower than reference value and not demonstrated a satisfactory reliability and validity, then some modifications were done as below.

\subsubsection{Research Model Modification}

Generally speaking, considering about the cronbach's alpha value of BI (0.653) was a little lower than reference value of 0.70 , the AVE values of HIL (0.526) and PBC (0.529) were only a little higher than the benchmark of 0.5 , which not demonstrated a satisfactory reliability and validity. Therefore, the variable of "Health Status (HS)" was added to modify the research model, hoping to obtain satisfactory results. The modified research model was shown in Figure 3.

Health status is a holistic concept that is determined by more than the presence or absence of any disease. It is often summarised by life expectancy or self-assessed health status, and more broadly includes measures of functioning, physical illness, and mental wellbeing [30]. In our previous questionnaire, participants were asked to rate their current health status on a 5-point Likert scale (excellent/good/moderate/poor/very poor). Machi Suka' research reported that health status could be connected to health information behavior [31]. Poor health users are more likely to perceive health risks, making them more actively seeking for health information through the social media [32]. And then it will affect the user's perception of social pressure and the difficulty of taking any action. In view of this, the variable of health status was added to our research model and we hypothesized as below.

H9: Health Status (HS) is positively associated with the attitudes toward the health information search behavior via social media (A).

H10: Health Status (HS) is positively associated with subject norms (SN) that is to say the perception of social pressure and motivation. 
Table 2. Latent variable correlations.

\begin{tabular}{cccc}
\hline Constructs & Average Variance Extracted (AVE) & Cronbachs' Alpha & Composite Reliability (CR) \\
\hline Health Information Literacy (HIL) & $\mathbf{0 . 5 2 6}$ & 0.819 & 0.869 \\
Gratification of Information (GI) & 0.640 & 0.860 & 0.899 \\
Gratification of Information Platform (GIP) & 0.577 & 0.756 & 0.844 \\
Attitudes Toward the Behavior (A) & 0.604 & 0.781 & 0.859 \\
Subjective Norms (SN) & 0.692 & 0.849 & 0.899 \\
Perceived Behavioral Control (PBC) & $\mathbf{0 . 5 2 9}$ & 0.713 & 0.816 \\
Behavior Intentions (BI) & 0.590 & $\mathbf{0 . 6 5 3}$ & 0.811 \\
\hline
\end{tabular}

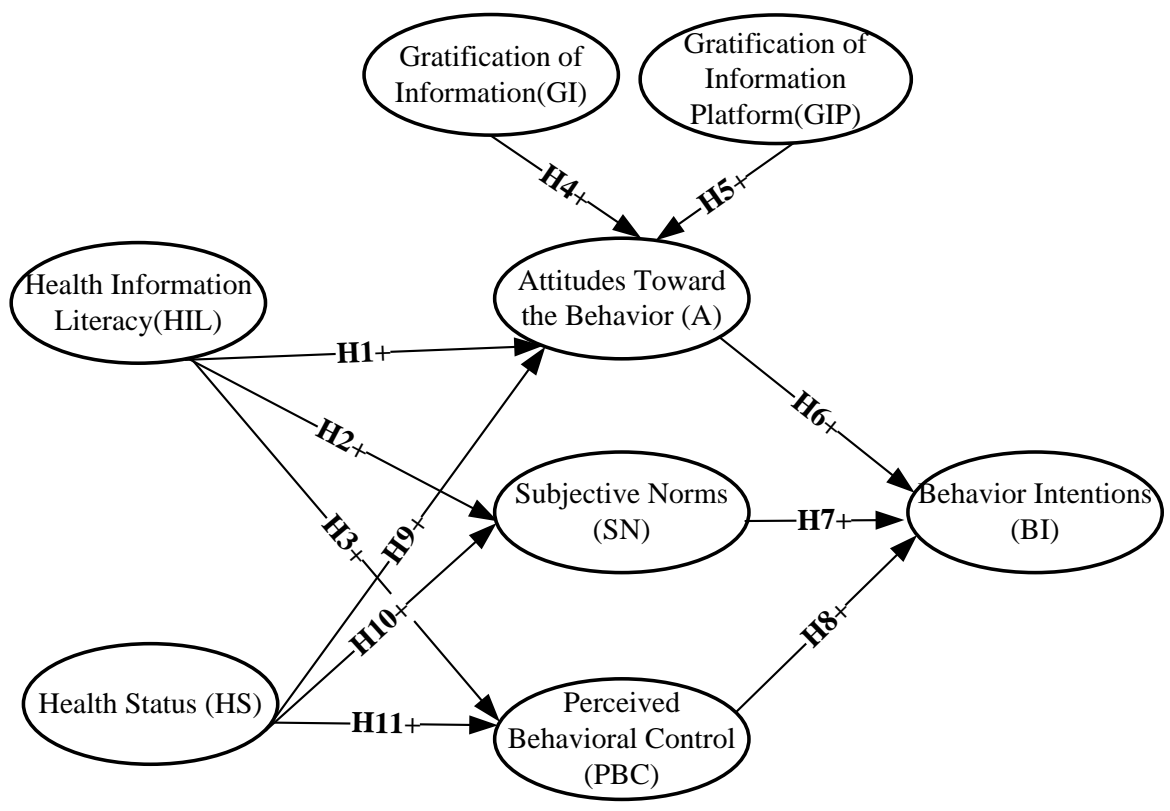

Figure 3. Modified research model.

H11: Health Status (HS) is positively associated with perceived behavioral control (PBC) namely the perceived degree of difficulty in performing the behavior.

\subsubsection{Reliability and Validity Evaluation of Modified Research Model}

As shown in Table 3, the values of AVE, Cronbachs' alpha and CR were all above their benchmarks in modified research model. Most of the numerical values were increased on the basis of the original, only a few values decreased slightly. What is worth mentioning was that the cronbach's alpha value of BI increased from 0.653 to 0.706 , which was higher than reference value of 0.70 . The AVE values of HIL and PBC were increased from 0.526, 0.529 to $0.620,0.573$ respectively, which were much higher than the benchmark of 0.5 compared with before. These indictors of Cronbach's alpha and CR coefficients in Table 3 suggested higher internal reliability than previous.

Table 4 showed the square roots of AVE and correlations between constructs. We could see that the square roots of each self construct's AVE were more than 0.727 in previous, and then were changed to 0.757 after modified. All values were increased in varying degrees after modified, and the square roots of each construct's AVE still larger than its correlations with other constructs, suggesting sufficient discriminant validity [33]. In sum, AVE, cronbach's alpha, CR and square roots of AVE demonstrated a satisfactory reliability and validity. According to the analyses above, the internal consistency and validity results enabled us to proceed to an estimation of the structural model. 
Table 3. Modified latent variable correlations.

\begin{tabular}{cccc}
\hline Constructs & Average Variance Extracted (AVE) & Cronbachs’ Alpha & Composite Reliability (CR) \\
\hline Health Information Literacy (HIL) & $\mathbf{0 . 5 2 6} \rightarrow \mathbf{0 . 6 2 0}$ & $0.819 \rightarrow 0.825$ & $0.869 \rightarrow 0.885$ \\
Gratification of Information (GI) & $0.640 \rightarrow 0.634$ & $0.860 \rightarrow 0.860$ & $0.899 \rightarrow 0.899$ \\
Gratification of Information Platform (GIP) & $0.577 \rightarrow 0.578$ & $0.756 \rightarrow 0.757$ & $0.844 \rightarrow 0.856$ \\
Attitudes Toward the Behavior (A) & $0.604 \rightarrow 0.677$ & $0.781 \rightarrow 0.804$ & $0.859 \rightarrow 0.840$ \\
Subjective Norms (SN) & $0.692 \rightarrow 0.723$ & $0.849 \rightarrow 0.902$ & $0.899 \rightarrow 0.930$ \\
Perceived Behavioral Control (PBC) & $\mathbf{0 . 5 2 9} \rightarrow \mathbf{0 . 5 7 3}$ & $0.713 \rightarrow 0.734$ & $0.816 \rightarrow 0.823$ \\
Behavior Intentions (BI) & $0.590 \rightarrow 0.660$ & $\mathbf{0 . 6 5 3} \rightarrow \mathbf{0 . 7 0 6}$ & $0.811 \rightarrow 0.820$ \\
Health Status (HS) & 0.590 & 0.719 & 0.823 \\
\hline
\end{tabular}

Notes: The values on left side are the original values, and on right side are the modified values.

Table 4. AVE square roots and correlation between constructs.

\begin{tabular}{|c|c|c|c|c|c|c|c|c|}
\hline & HIL & GI & GIP & A & $\mathrm{SN}$ & PBC & BI & HS \\
\hline HIL & $0.725 \rightarrow 0.796$ & & & & & & & \\
\hline GI & $0.469 \rightarrow 0.479$ & $0.800 \rightarrow 0.880$ & & & & & & \\
\hline GIP & $0.458 \rightarrow 0.478$ & $0.651 \rightarrow 0.657$ & $0.760 \rightarrow 0.770$ & & & & & \\
\hline A & $0.363 \rightarrow 0.463$ & $0.557 \rightarrow 0.654$ & $0.462 \rightarrow 0.463$ & $0.777 \rightarrow 0.803$ & & & & \\
\hline $\mathrm{SN}$ & $0.490 \rightarrow 0.497$ & $0.438 \rightarrow 0.438$ & $0.398 \rightarrow 0.398$ & $0.275 \rightarrow 0.288$ & $0.832 \rightarrow 0.842$ & & & \\
\hline PBC & $-0.358 \rightarrow-0.358$ & $-0.340 \rightarrow-0.350$ & $-0.420 \rightarrow-0.424$ & $-0.374 \rightarrow-0.385$ & $-0.253 \rightarrow-0.256$ & $0.727 \rightarrow 0.757$ & & \\
\hline $\mathrm{BI}$ & $0.464 \rightarrow 0.469$ & $0.451 \rightarrow 0.451$ & $0.450 \rightarrow 0.453$ & $0.406 \rightarrow 0.456$ & $0.667 \rightarrow 0.705$ & $-0.292 \rightarrow-0.342$ & $0.768 \rightarrow 0.785$ & \\
\hline HS & 0.306 & 0.470 & 0.440 & 0.502 & 0.478 & 0.301 & 0.490 & 0.790 \\
\hline
\end{tabular}

Notes: The values on left side are the original values, and on right side are the modified values.

\subsection{Interpretation of Structural Model Testing}

The standardized solution estimated by the PLS 3.0 program was used for interpreting the structural relation results. Path coefficients for each value from the models were shown in Figure 4 and the modified results were shown in Figure 5. Six paths exhibited a $P$-value of $<0.001$, one path of $<0.05$ and H8 path was exhibited of no significance in previous. But after the modification, eight paths exhibited a P-value of $<0.001$, one path $<0.01$, two paths $<0.05$, there were 4 path coefficients have been greatly improved. The most obvious was that the impact of perceived behavioral control (H8) was increased from -0.041 to -0.246 and exhibited a great significance, followed the impact of gratification of information ( $\mathrm{H} 4)$ on attitudes toward the behavior was increased from 0.145 to 0.345 , attitudes toward the behavior (H6), subjective norms (H7) on behavior intentions were increased from $0.231,0.587$ to $0.451,0.607$ respectively. The remaining path coefficients had varying degrees of increase. Therefore, we analyzed the results according to the modified results and they would be discussed as below.

\section{Discussion and Conclusions}

From Figure 5, we could see that all the 11 hypotheses were well validated, proving that we had successfully constructed the model of health information seeking behavior. We discuss the results as follows.

There have been many multi-angle analyses of the health information seeking behavior. However the seeking behaviors were often not the same with different investigators. Ghaddar and Valerio found that health literacy was positively associated with seeking health information online and exposure to MedlinePlus [34]. The high e-Health literacy scores could increase the likelihood of having adequate health literacy. Once there have been reported patients with limited health literacy may lack either internet access or skills necessary to utilize health information. However Natalia Gutierrez and Kindratt reported that there were no statistically significant 


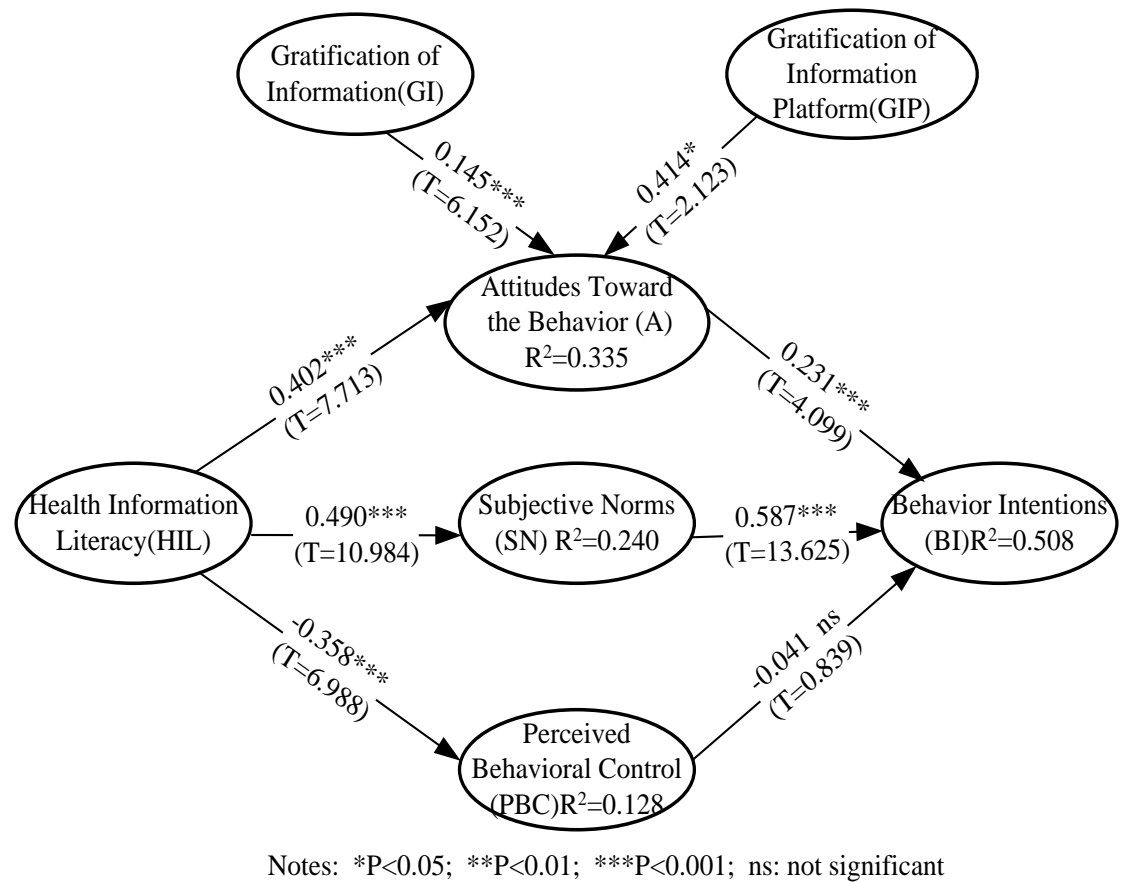

Figure 4. Results of PLS analysis.

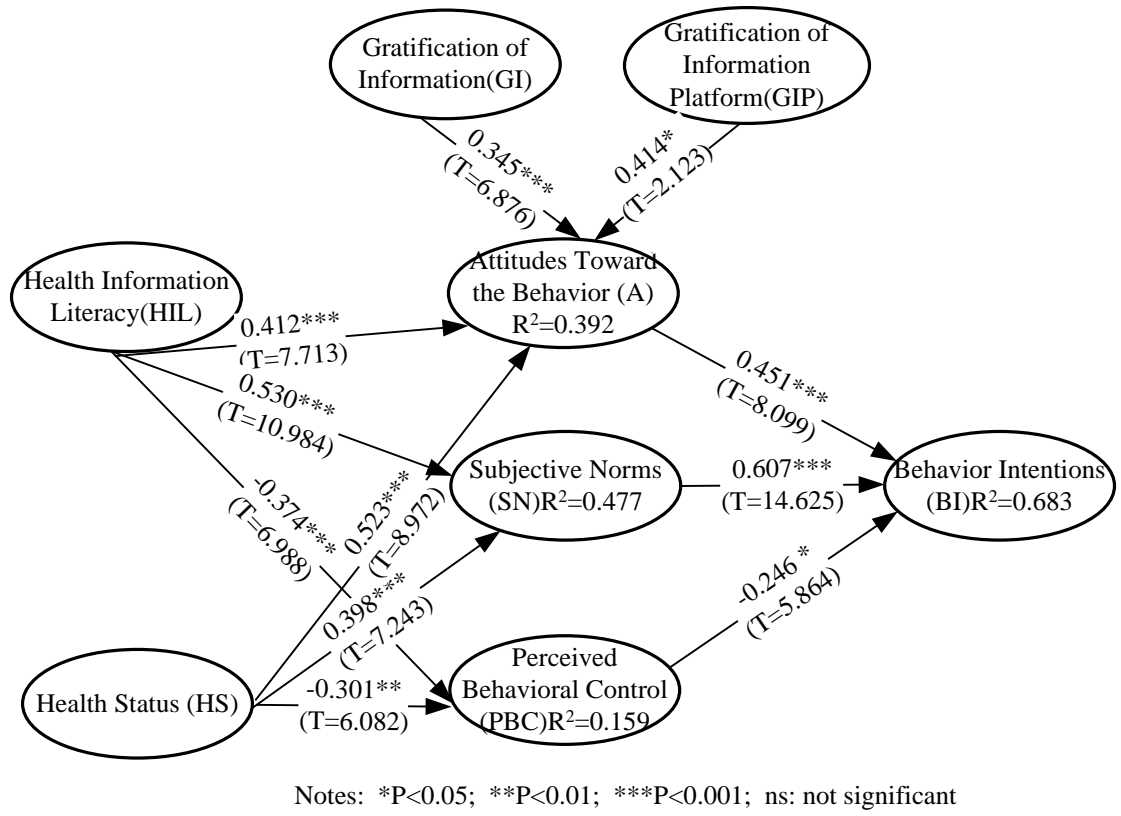

Figure 5. Results of modified PLS analysis.

differences between patients with limited and adequate health literacy and their primary information source [20]. Controversies existed over whether health literacy was associated with health information seeking behavior. In our research, information literacy was added to health literacy to compose health information literacy which proved to have a significant influence on the attitudes toward health information seeking behavior (H1), subject norms (H2) and perceived behavioral control (H3) respectively. This paper confirmed that people with more health information literacy preferred to use social media in the context of health information seeking, consistent 
with previous research [35]. From the results of PLS analysis, we could easily see that health information literacy was positively associated with attitudes and subject norms while it was negatively associated with perceived behavioral control. And the contributions of health information literacy to attitudes and subject norms were more important than that of perceived behavioral control. It was might because of that health suffers trend to be younger, adequate health information literacy could help them reduce the perceived degree of difficulty in performing the behavior.

Hypotheses $\mathrm{H} 4$ and $\mathrm{H} 5$ were both verified in our research as in many previous studies applying UGT to explain the relationship between gratifications and attitudes toward searching health information on different kinds of social media and platform use. As previously described that the degree of satisfaction to the web site providing information directly decided the future of potential consumers [24]. In a word, the more gratified information and social media platform presented, the more positive attitude consumers would hold in the process of searching for health information.

As previously proved by Ajzen and Fishbein [16], hypotheses H6, H7 and H8 were well validated in our research, but the impacts of perceived behavioral control (H8) on behavior intentions were negative and the contribution was less important than that of attitudes toward the behavior and subjective norms. In the literature Understanding Middle-Aged Women's Health Information Seeking on the Web: A Theoretical Approach [36], perceived behavioral control was shown to be a relatively weaker predictor than attitudes and motivations concerning. They thought that the underlying reasons for the limited effect of perceived behavioral control were likely due to the characteristics of the study sample. We agreed with that statement and considered the other possible reason for this kind of situation was the interaction between perceived behavioral control and its results have not been found and explained; besides the introduction of health information literacy and health status variables might affect the role of other variable like perceived behavioral control more or less. In this respect we would do further validation in future research. In general, this part had strongly indicated that maintain a positive attitude to find health information and keep health communication with important others will positively promote health information search behavior.

Hypotheses H9, H10, H11 were verified in our modified research model. As previously described that poor health users were more likely to perceive health risks, and making them more actively seeking for health information through the social media. From the results of modified PLS analysis, we could easily see that the impact of health status on attitudes toward the health information (H9), subject norms (H10), perceived behavioral control (H11) were roughly the same as health information literacy an them(H1, H2, H3). Health status was positively associated with attitudes and subject norms while it was negatively associated with perceived behavioral control. And the contributions of health status to attitudes and subject norms were more important than that of perceived behavioral control.

Our results also indicated that demographic factors of age, gender and profession had certain influence on health information seeking behavior via social media. The highest proportion of health surfers occurred in the 18 - 29 years age group, female were more likely to seek online health information than males, students and teachers were of the most proportion of respondents, who typically shared health information on Wechat. This higher prevalence may also be a reflection of greater health awareness of this group.

\section{Theoretical and Practical Implications}

TPB is a applicable model for analyzing influencing factors of consumer health information seeking behavior via social media. In this paper, we explored scientific, reasonable, simple and feasible measurements to develop theoretical research, and the modified model constructed by us was proved to be of great success. The health information literacy, gratifications of information and its platform, health status were proved to be strongly effective measurements in our study. Furthermore, they could be used as exogenous variable of this relevant specific behavior.

The results can also have practical implications for understanding the influencing factors of consumer health information seeking behavior via social media and developing more tailored social media for health surfers. It was reported that the true spirit of user-centered design was to ensure accessibility and functionality across a diverse group of end users [37]. We need to ensure that we sent patients to social media are simple to access, easy to understand, developed in literacy-appropriate and language-appropriate ways.

Health information literacy was proved to have a significant influence on attitudes toward health information 
seeking behavior, subject norms and perceived behavioral control respectively. The challenge seems to be the need for information literacy activities relating to health literacy or health information literacy skills and competencies to be developed and encouraged within consumers. For example, it is of great benefit to hold a variety of health information inquiry competitions, health information analysis activities, health information science popularization and other activities strengthen users' health education and self-management.

Gratification of health information and its platform had been proved to have a positive effect on health attitude and behavior intention. Therefore, it is imperative for the government departments to increase the popularity of the network and to improve the network accessibility. At the same time, it is particularly important to improve the satisfaction of health information, which requires the improvement of the health information filtering mechanism, the development of health information standards, and improve the readability of health information. In addition, optimizing the steps of health information retrieval, adding the column of readers, contact us and other reader training programs to improve platform satisfaction is another effective strategy.

As the same with health information literacy, health status was also proved to have a significant influence on attitudes toward health information seeking behavior, subject norms and perceived behavioral control respectively. There is no doubt that increasing the level of consumers' health status and promoting health information seeking behavior is a process of mutual influence. As the ultimate goal of health promotion and the influence factor of health information seeking behavior, more attention should be given to the health status.

\section{Fund}

The paper was supported by the National Social Science Foundation of China (No. 13BDQ004; No. 14CTQ022).

\section{References}

[1] Dizon, D.S., Graham, D., Thompson, M.A., et al. (2012) Practical Guidance: The Use of Social Media in Oncology Practice. Journal of Oncology Practice, 8, e114-e124. http://dx.doi.org/10.1200/JOP.2012.000610

[2] Martinello, N. and Donelle, L. (2012) Online Conversations among Ontario University Students: Environmental Concerns. Informatics for Health and Social Care, 37, 177-189. http://dx.doi.org/10.3109/17538157.2012.678448

[3] Keselman, A., Browne, A.C., et al. (2008) Consumer Health Information Seeking as Hypothesis Testing. Journal of the American Medical Informatics Association, 15, 484-495. http://dx.doi.org/10.1197/jamia.M2449

[4] Fox, S. (2006) Online Health Search 2006. Pew Internet and American Life Project. http://www.pewinternet.org/files/old-media/Files/Reports/2006/PIP_Online_Health_2006.pdf.pdf

[5] Fox, S. and Rainie, L. (2000) The Online Health Care Revolution. Pew Internet \& American Life Project. http://www.pewinternet.org/

[6] Chou, W.S., Hunt, Y.M., Beckjord, E.B., et al. (2009) Social Media Use in the United States: Implications for Health Communication. Journal of Medical Internet Research, 11, e48. http://dx.doi.org/10.2196/jmir.1249

[7] Lambert, S.D. and Loiselle, C.G. (2007) Health Information-Seeking Behavior. Qualitative Health Research, 17, 1006-1019. http://dx.doi.org/10.1177/1049732307305199

[8] Rees, C.E. and Bath, P.A. (2001) Information-Seeking Behaviors of Women with Breast Cancer. Oncology Nursing Forum, 28, 899-907.

[9] Kolekofski, K.E. and Heminger, A.R. (2003) Beliefs and Attitudes Affecting Intentions to Share Information in an Organizational Setting. Information \& Management, 40, 521-532. http://dx.doi.org/10.1016/S0378-7206(02)00068-X

[10] Longo, D.R., Schubert, S.L., Wright, B.A., et al. (2010) Health Information Seeking, Receipt, and Use in Diabetes Self-Management. Annals of Family Medicine, 8, 334-340. http://dx.doi.org/10.1370/afm.1115

[11] Zhang, S.J. and Du, J. (2010) Health Information Literacy Should Become the Critical Point of Health Literacy Promotion for the Chinese Public. Medical Informatics, 31, 45-49.

[12] MLA (2003) What Is Health Information Literacy? https://www.mlanet.org

[13] Andsager, J.L. (2014) Research Directions in Social Media and Body Image. Sex Roles, 71, 407-413. http://dx.doi.org/10.1007/s11199-014-0430-4

[14] Palmgreen, P. and Rayburn, J.D. (1982) Gratifications Sought and Media Exposure: An Expectancy Value Model. Communication Research, 9, 561-580. http://dx.doi.org/10.1177/009365082009004004

[15] Tolma, E.L., Reininger, B.M., Evans, A., et al. (2006) Examining the Theory of Planned Behavior and the Construct of Self-Efficacy to Predict Mammography Intention. Health Education \& Behavior, 33, 233-251.

http://dx.doi.org/10.1177/1090198105277393 
[16] Ajzen, I. and Fishbein, M. (2005) The Influence of Attitudes on Behavior. In: Albarracin, D., Johnson, B.T. and Zanna, M.P., Eds., The Handbook of Attitudes, Vol. 173, Psychology Press, Hove, 173-222.

[17] Jiang, F., Lu, S., Hou, Y. and Yue, X. (2013) Dialectical Thinking and Health Behaviors: The Effects of Theory of Planned Behavior. International Journal of Psychology, 48, 206-214. http://dx.doi.org/10.1080/00207594.2012.656130

[18] Schillinger, D., Bindman, A., Wang, F., Stewart, A. and Piette, J. (2004) Functional Health Literacy and the Quality of Physician-Patient Communication among Diabetes Patients. Patient Education \& Counseling, 52, 315-323. http://dx.doi.org/10.1016/S0738-3991(03)00107-1

[19] Crook, B., Stephens, K.K., Mackert, M. and Donovan, E.E. (2015) Sharing Health Information and Influencing Behavioral Intentions: The Role of Health Literacy, Information Overload, and the Internet in the Diffusion of Healthy Heart Information. Health Communication, 31, 60-71. http://dx.doi.org/10.1080/10410236.2014.936336

[20] Gutierrez, N., Kindratt, T.B., Pagels, P., Foster, B. and Gimpel, N.E. (2014) Health Literacy, Health Information Seeking Behaviors and Internet Use among Patients Attending a Private and Public Clinic in the Same Geographic Area. Journal of Community Health, 39, 83-89. http://dx.doi.org/10.1007/s10900-013-9742-5

[21] Sundar, S.S. and Limperos, A.M. (2013) Uses and Grats 2.0: New Gratifications for New Media. Journal of Broadcasting \& Electronic Media, 57, 504-525. http://dx.doi.org/10.1080/08838151.2013.845827

[22] Cappel, J.J. and Huang, Z. (2007) A Usability Analysis of Company Websites. Journal of Computer Information Systems, 48, 117-123.

[23] Nathan, R.J. and Yeow, P.H. (2011) Crucial Web Usability Factors of 36 Industries for Students: A Large-Scale Empirical Study. Electronic Commerce Research, 11, 151-180. http://dx.doi.org/10.1007/s10660-010-9054-0

[24] Turban, E. and Gehrke, D. (2000) Determinants of E-Commerce Website. Human Systems Management, 19, 111-120.

[25] Doll, W.J. and Torkzadeh, G. (1988) The Measurement of Enduser Computing Satisfaction. Mis Quarterly, 12, 259274. http://dx.doi.org/10.2307/248851

[26] Chin, W.W., Marcolin, B.L. and Newsted, P.R. (2003) A Partial Least Squares Latent Variable Modeling Approach for Measuring Interaction Effects: Results from a Monte Carlo Simulation Study and an Electronic-Mail Emotion/Adoption Study. Information Systems Research, 14, 189-217. http://dx.doi.org/10.1287/isre.14.2.189.16018

[27] Fornell, C. and Larcker, D.F. (1981) Evaluating Structural Equation Models with Unobservable and Measurement Errors. Journal of Marketing Research, 18, 39-50. http://dx.doi.org/10.2307/3151312

[28] Zha, X., Li, J. and Yan, Y. (2013) Information Self-Efficacy and Information Channels: Decision Quality and Online Shopping Satisfaction. Online Information Review, 37, 872-890. http://dx.doi.org/10.1108/OIR-09-2012-0156

[29] Reynaldo, J.A. and Santos, A. (1999) Cronbach's Alpha: A Tool for Assessing the Reliability of Scales. Journal of Extension, 37, 1-4.

[30] Richters (2003) SIHW Health Status. http://www.aihw.gov.au/male-health/health-status/

[31] Suka, M., Odajima, T., Okamoto, M., et al. (2015) Relationship between Health Literacy, Health Information Access, Health Behavior, and Health Status in Japanese People. Patient Education \& Counseling, 98, 660-668. http://dx.doi.org/10.1016/j.pec.2015.02.013

[32] Wang, M. (2013) Research on Critical Factors of the Behavior of Obtaining Online Health Information in America. Journal of Information Resources Management, 3, 47-58.

[33] Straub, D.W., Gefen, D. and Boudreau, M.-C. (2000) Structural Equation Modeling and Regression: Guidelines for Research Practice. Communications of the Association for Information Systems, 4, Article 7.

[34] Ghaddar, S.F., Valerio, M.A., Garcia, C.M. and Hansen, L. (2012) Adolescent Health Literacy: The Importance of Credible Sources for Online Health Information. Journal of School Health, 82, 28-36. http://dx.doi.org/10.1111/j.1746-1561.2011.00664.x

[35] Urmimala, S., Karter, A.J., et al. (2011) Social Disparities in Internet Patient Portal Use in Diabetes: Evidence That the Digital Divide Extends Beyond Access. JAMA, 18, 318-321.

[36] Yoo, E.Y. and Robbins, L.S. (2008) Understanding Middle-Aged Women's Health Information Seeking on the Web: A Theoretical Approach. Journal of the American Society for Information Science \& Technology, 59, 577-590. http://dx.doi.org/10.1002/asi.20766

[37] Lyles, C.R. and Sarkar, U. (2015) Health Literacy, Vulnerable Patients, and Health Information Technology Use: Where Do We Go from Here? Journal of General Internal Medicine, 30, 271-272. http://dx.doi.org/10.1007/s11606-014-3166-5 


\section{Submit or recommend next manuscript to SCIRP and we will provide best service for you:}

Accepting pre-submission inquiries through Email, Facebook, LinkedIn, Twitter, etc.

A wide selection of journals (inclusive of 9 subjects, more than 200 journals)

Providing 24-hour high-quality service

User-friendly online submission system

Fair and swift peer-review system

Efficient typesetting and proofreading procedure

Display of the result of downloads and visits, as well as the number of cited articles

Maximum dissemination of your research work

Submit your manuscript at: http://papersubmission.scirp.org/ 